\title{
TRÊS CENAS DE UMA VIDA
}

Meiko Shimon

RESUMO: São analisados três contos de Tanagokoro no shôsetsu (Contos que Cabem na Palma da Mão) de Kawabata Yasunari intitulados Obrigado, Castidade sob o Telhado e Cortar as Unhas pela Manhã. Esses contos possuem vários aspectos que permitem interpretá-los como uma trilogia, pois narram três épocas da vida de uma mulher. No primeiro e no último, Kawabata aborda os episódios que modificaram a vida das protagonistas e, no segundo, faz um corte do cotidiano de uma delas. Estas pequenas obras são mais uma amostra da postura desse escritor que acreditava no lado belo e benevolente do ser humano mesmo nas situações mais adversas.

ABSTRACT: Three short stories of Kawabata Yasunari's Tanagokoro no shôsetsu (Short stories that fit in the palm of a hand) are analysed. They are: Thank You, Chastity under the roof and Cut the nails in the morning. They have many aspects which allow to interpret them as a trilogy that tells about the periods of a woman's life. In the first one and in the last one, Kawabata deals with episodes that changed the protagonists's lives. In the second one, he approaches daily life of one of them. These short stories are one more proof of this writer's attitude, who believed in the beautiful and benevolent side of the human being, even in unhappy situations.

PALAVRAS-CHAVE: Kawabata Yasunari, Contos que Cabem na Palma da Mão, Obrigado, Castidade sob o Telhado, Cortar as Unhas pela Manhã.

KEYWORDS: Kawabata Yasunari, Short Stories that fit in the palm of a hand, Thak You, Chastity under the roof, Cut the nails in the morning. 
Uma mulher pobre que mora numa pequena cidade portuária resolve viajar de ônibus, levando sua filha para uma cidade maior, distante sessenta quilômetros, onde há uma estação ferroviária. Só esse fato já é um acontecimento extraordinário na vida dessa gente simples do interior do Japão, dos anos vinte. É a primeira parte da breve narrativa intitulada Obrigado (Arigatô), de Kawabata Yasunari (1989-1972), publicada em 1925, um dos cento e quarenta e oito contos do gênero de Tanagokoro no shôsetsu (Contos que Cabem na Palma da Mão).

A narrativa do conto Obrigado desenvolve-se em um estilo cadenciado e a descrição do motorista, que parece um boneco autômato, proporciona uma alegre expectativa ao leitor. No entanto, logo vem a revelação de uma realidade cruel. A mãe estava levando a filha para vendê-la à prostituição. A partir dessa revelação, era de se esperar um drama do trágico destino da menina, mas o autor não conduz a história para este rumo. Ele retoma o ritmo ligeiro da narrativa e mostra a personalidade do motorista, um homem correto, respeitador e, sobretudo, gentil, até para com os cavalos: ele saúda e agradece a tudo e a todos que encontra pelo caminho. Assim, não seria de se estranhar que a mocinha encontrasse sua salvação - ainda que temporária - neste homem.

Não era raro no Japão, naquela época, que os pais pobres vendessem suas filhas para se tornarem gueixas ou, na hipótese pior, prostitutas. Tragédias como esta foram exploradas com muito gosto na literatura japonesa do passado, sobretudo no teatro kabuki, que atribuía heroísmo a essas moças, principalmente quando se ofereciam voluntariamente a tal sacrifício para salvar as finanças de seus pais. Os escritores japoneses modernos que antecederam Kawabata Yasunari, ou mesmo seus contemporâneos, trataram o mesmo assunto de uma forma muito diversa da de Obrigado. Hatori Tetsuya observa que tanto os escritores naturalistas quanto os modernistas ou proletários $^{1}$ descreviam, propositadamente, o lado obscuro do homem, sob o pretexto de desvendar a verdade da natureza humana e as contradições da sociedade. Enquanto os naturalistas detinham-se na análise de conflitos internos do indivíduo e os proletários ocupavam-se em denunciar os problemas da injustiça social, Kawabata dedicava-se à busca do lado belo e benevolente do ser humano. Ao contrário da tradição moderna ${ }^{2}$ da literatura que vinha sendo fundamentada na "descrença do sexo feminino" e "descrença do ser humano", Kawabata procurava estabelecer uma literatura baseada nos ideais de "amor à humanidade" e "salvação da humanidade"3.

Nos Contos que Cabem na Palma da Mão, Kawabata Yasunari aborda muitas vezes as mulheres que vivem em condições adversas, do ponto de vista social e/ou afetivo, sem que sua narrativa recaia em sentimentalismo ou em comiseração. $O$ escritor que, ainda jovem, declarara sentir-se mais à vontade no bairro Asakusa do que no de Ginza e encantar-se mais pelas operárias que deixam a fábrica após o expediente do

1. Os movimentos literários referidos neste trabalho são exclusivamente dos escritores japoneses.

2. Literatura moderna japonesa: a partir de 1885, quando surgiu Shôsetsu shinzui, de Tsubouchi Shôyô(18591935).

3. Tetsuya Hatori, Sakka Kawabata Yasunari no tenkai, Tóquio, Kyôiku Shuppan Sentâ, 1993, pp. 233-234. 
que pelas senhoritas colegiais ${ }^{4}$, demonstra total empatia ao narrar momentos de alegrias e frustrações das dançarinas e prostitutas. Kawabata, que ficou conhecido pela sua refinada sensibilidade estética com os romances como Senbazuru (Nuvens de Pássaros Brancos) e Koto (Quioto), afirmou, no ano em que se preparava para escrever Yukiguni (País das Neves), em 1934, que preferia "a beleza da sujidade"5.

As mulheres trabalhadoras da série de contos chamados Izu-mono (relacionados com Izu) - entre eles Obrigado - e as dançarinas de Asakusa-mono (relacionados com Asakusa) são exemplos fartos dessa sua inclinação. A mocinha de Obrigado não escapará do seu destino de ser vendida pela própria mãe na primavera seguinte, mas, pelo menos, terá uma feliz recordação do seu primeiro amor. O seu futuro, certamente, não será muito diferente do das protagonistas dos contos Castidade sob o Telhado (Yane no shita no teisô), de 1925, e Cortar as Unhas pela Manhã (Asa no tsume), de 1926, que serão analisados mais adiante. Nesses, as protagonistas já se encontram afundadas na vida, no entanto não perdem sua "pureza" espiritual de outrora, e cada uma procura fazer o melhor possível para cumprir o seu desígnio.

A narrativa de Obrigado é composta praticamente por diálogos e pela descrição do comportamento do motorista e desenvolve-se colocando em primeiro plano o motorista e seu modo de ser, a partir da sucessão dos acontecimentos, ao longo do percurso de sessenta quilômetros. A mocinha quase não tem participação e, ao contrário da eloqüência de sua mãe, não emite um único som. Porém, ao terminar a leitura, temos a sensação de que é ela a personagem principal. Notamos também uma característica marcante de Kawabata: a repetição, não só de vocábulos, mas, inclusive, de expressões inteiras. Em uma narrativa tão curta como esta, seria de se estranhar o uso de tantas repetições, quando o primordial seria a economia de vocábulos, porém, como observou Hasegawa Izumi, nenhuma repetição, no caso de Kawabata, é gratuita e encerra um mesmo significado ${ }^{6}$.

No conto Obrigado, temos o primeiro e último parágrafos idênticos:

Este é um ano de farta colheita de caqui e de um belo outono nas montanhas.

No início da narrativa, introduz-se um ambiente rural, tranqüilo e pitoresco, indicando a época em que se desenrolam os acontecimentos descritos, que é o outono; ao passo que, no final, mostra-se a paisagem como fruto de toda gratidão sentida por todos que tiveram contato com o motorista. E é por isso que fazem sentido as inúmeras repetições de "Obrigado!"

O outro exemplo é ainda mais sutil. No caminho de ida:

[...] a moça está com a luz do seu olhar aprisionada pelo ombro reto do motorista.

4. Yasunari Kawabata, Bungakuteki jijoden. In Kawabata Yasunari Zenshû, V. 13, Tóquio, 1976, p. 105.

5. Kawabata, idem.

6. Toshio Matsuzaka, "Natsu no kutsu ron" In Kawabata Yasunari "Tanagokoro no shôsetsu" kenkyû, Tóquio, Kyôiku Shuppan, 1983. 
[...] a moça está com a luz do seu olhar aprisionada pelo ombro terno do motorista.

A substituição apenas da palavra 'reto' por 'terno' exprime a mudança que se operara no sentimento íntimo da garota, como também no do motorista e conseqüentemente na relação entre os dois.

Por sua vez, a protagonista de Castidade sob o Telhado tem uma vida errante, escolhe aonde e com quem passa cada noite, segundo a sorte de quem chega primeiro atendendo ao seu convite. Entretanto, ela conserva a inocência de uma criança e crê manter-se casta naquela noite, sob o telhado que a acolheu. Para o olho do narrador que a observa com simpatia, ela é a "flor de yûgao", possui "um belo sorriso", tem "calcanhares inocentes" e acredita piamente no Deus cristão.

A narrativa apresenta uma técnica expressiva tipicamente neo-sensorialista (shinkankakuha), com uma linguagem repleta de imagens sensoriais inusitadas, como:

ela florescia serena como a flor yûgao

Os brotos tenros,... receberam suaves toques do ar em suas cútis delicadas, lamentavam... a chegada do seu primeiro entardecer

as casas desta grande cidade observavam-na friamente

Chama atenção a comparação com a flor branca yûgao: a cor branca que simboliza a pureza e sua presença noturna, a própria imagem dessa mulher. $\mathrm{O}$ nome da flor yûgao evoca também a trágica heroína de Genji monogatari ${ }^{8}$, que fora seduzida pelo príncipe Hikaru. Uma mulher tão suave e frágil, que não suportara o fogo da paixão de uma noite, perecendo ao amanhecer. Contudo, nesta moderna yûgao não há a sombra da tragédia; ao contrário da passiva personagem clássica, ela é uma pessoa capaz de lutar para garantir seu espaço neste mundo.

Já a protagonista de Cortar as Unhas pela Manhã vive em uma condição oposta à da mulher de Castidade sob o Telhado. Reside no segundo andar de uma casa e "todas as noites aparecia um homem diferente ao seu encontro" Apesar de pobre, a ponto de não ter nem um mosquiteiro, ela tem um namorado e sonha com o dia de se casar com ele. Enquanto que o "homem de bengala" é apenas mais um que garante uma noite de pouso para a personagem de Castidade sob o Telhado, sem nenhuma participação no desenrolar da narrativa, o "velho", de Cortar as Unhas pela Manhã, interfere no curso da vida da moça e o modifica, por meio de um mosquiteiro branco que compra para ela. Ele é um benfeitor como o "motorista" de Obrigado, mas difere no aspecto de que, naquele caso, a felicidade da mocinha era apenas até a primavera (se é que há felicidade) e aqui a paz encontrada pela protagonista é verdadeira. $\mathrm{Na}$

7. Yûgao: planta da família de cabaça-amargosa, de flores alvas, abrem-se ao entardecer e permanecem durante a noite. A palavra yûgao significa, literalmente, "o rosto do entardecer".

8. Genji monogatari: autoria de Murasaki Shikibu (973-1014?), romance escrito não antes de 1001. 
noite em que ganhou o mosquiteiro, "ela caiu num sono profundo que não tivera em alguns meses" e "nem mesmo notou quando o velho foi embora pela manhã". Essa noite significa uma espécie de cerimônia de passagem para recuperar a pureza perdida. O mosquiteiro branco purifica "a mulher" e o "quarto", e o homem idoso lembra a figura da divindade mitológica das lendas japonesas, que surgem para ajudar a pessoa em dificuldade, como aconteceu com Yamasachi?.

A moça sentada sobre o mosquiteiro branco parece uma flor de lótus aos olhos do rapaz, seu namorado, enquanto ela imagina ser uma noiva de vestido branco. A idéia da purificação completa - salvação - da mulher está explícita na imagem de "grande flor de lótus branca", uma alusão à Bodhisattwa ${ }^{10}$.

A análise realizada até aqui evidencia uma certa continuidade entre os três contos, tanto na questão temporal quanto no conteúdo. As três heroínas - a mocinha desajeitada do interior de Obrigado, a alegre e inocente mulher da grande metrópole de Castidade sob o Telhado, e a tímida e dedicada mulher de Cortando as Unhas pela Manhã podem, ou não, ser a mesma pessoa. Contudo, há vários elementos que permitem interpretar os contos como sendo três cenas da vida de uma mulher nestas condições.

- Obrigado - Final do outono. A mocinha só irá para grande cidade na primavera seguinte, porém o inverno que se aproxima simboliza as dificuldades que terá que passar no futuro;

- Castidade sob o Telhado - Março é o começo da primavera no Japão. Ela sobreviveu ao rigor do inverno e floresce no alto da colina. Parece não possuir passado nem futuro, vive apenas do momento. Embora efêmera como yûgao, ela alcançou certa paz;

- Cortar as Unhas pela Manhã - Começo do outono. Ao recordar os dias de sua infância, ela recupera o passado; sua esperança de se casar com o namorado é a expectativa de um futuro melhor, e sentir-se como uma noiva, pelo toque do linho branco, é uma alusão ao seu presente purificado.

Assim, através desta personagem, a vida readquire o seu valor e restabelece seu curso, deixando espreitar uma luz no futuro destas mulheres. Teria sido por acaso que o ciclo do ano se completara também?

\section{OBRIGADO}

Este é um ano de farta colheita de caqui e de um belo outono nas montanhas.

$O$ pequeno porto ficava na extremidade sul da península. Um motorista de uniforme amarelo com a gola roxa vinha descendo do andar de cima da sala de espera dos passageiros, onde havia uma pequena venda de confeitos ordinários. Defronte, um ônibus vermelho o aguardava com sua bandeirinha roxa erguida.

9. Lenda de Umisachi Yamasachi (Irmãos pescador e caçador).

10. Conhecida como Deusa da Misericórdia. Corresponde a Avalokitêsvara, em nome sânscrito. 
Uma mulher levantou-se, apertando o saquinho de confeitos, e falou ao motorista, que amarrava caprichosamente o cordão dos sapatos.

- Ah! Hoje é a sua vez. Que bom. Deve ser um bom sinal para esta menina ser levada pelo "seu Obrigado" Talvez ela tenha muita boa sorte.

O motorista olhou a moça que estava ao lado, mas nada falou.

- Ficar adiando sempre não vai resolver, né? E daqui a pouco é o inverno. Eu tenho pena de mandá-la para longe com o tempo frio. Já que tenho que fazer isso, é melhor agora, que o tempo está bom. Assim, eu decidi levá-la.

Acenando com a cabeça, calado, o motorista se encaminha como um soldado e endireita a almofada do seu assento.

-Vovó, sente-se no primeiro banco. Quanto mais na frente, menos balança. Pois o caminho é longo.

A mãe está indo para a cidade onde passa o trem, a quinze $r i^{11}$ para o Norte, a fim de vender sua filha.

Balançando-se na estrada montanhosa, a moça está com a luz do seu olhar aprisionada pelo ombro reto do motorista. $\mathrm{O}$ uniforme amarelo vai se ampliando como o universo nos seus olhos. Através dos ombros, as montanhas se dividem e vão escoando para trás. $\mathrm{O}$ carro tem que transpor os dois pontos altos do caminho da montanha.

Alcança a diligência. Esta, encosta na beira da estrada.

- Obrigado.

Com uma voz clara e límpida, o motorista, numa intrépida continência, abaixa a cabeça como um pica-pau.

Encontra-se com a carreta carregada de madeira. A carreta encosta à beira da estrada.

- Obrigado.

- Carroça grande, puxada por um homem.

- Obrigado.

Riquixá.

- Obrigado.

Cavalo.

- Obrigado.

Mesmo que ultrapasse trinta carros em dez minutos, ele não perde suas boas maneiras. Ele não perde essa postura mesmo que percorra os cem $r i$ a toda velocidade. É como um tronco reto de cedro, simples e espontâneo.

O carro, que saíra do porto depois das três da tarde, acende a luz no meio do caminho. Cada vez que se encontra com um cavalo, o motorista sempre desliga a lanterna do carro para o animal. E assim,

- Obrigado.

- Obrigado.

- Obrigado.

Ele é o motorista com melhor reputação entre as diligências, as carroças e os cavalos, nos quinze $r i$ da estrada.

Descendo na penumbra do terminal da praça, a filha sente o corpo balançar e as pernas flutuarem e, cambaleante, ela se apóia na mãe.

11. 1 ri equivale a cerca de $4 \mathrm{~km}$. 
- Espere aqui. Fala a mãe, que corre atrás do motorista.

- Olhe, minha filha está dizendo que gosta de você. Eu lhe peço. Eu imploro. De amanhã em diante, de qualquer modo, ela vai virar brinquedo de homens estranhos. É verdade, não é? Até mesmo uma senhorita da cidade, se viajasse dez ri no seu ônibus...

Ao amanhecer do dia seguinte, o motorista sai da pensão onde pernoitou e vai atravessando a praça com a postura de um soldado. Atrás dele, mãe e filha correm em passos miúdos. $\mathrm{O}$ ônibus vermelho que saiu da garagem o aguarda com sua bandeirinha roxa erguida e espera o primeiro trem.

A filha sobe primeiro e, umedecendo os lábios secos, acaricia o couro preto do banco do motorista. Sentindo o frio matinal, a mãe junta as mangas do seu quimono.

- Ai, ai. Vai levar a minha filha de volta? Agora de manhã, ela me chora e você me repreende. Minha compaixão foi o erro. Levá-la de volta eu levo, mas entenda que é só até a primavera, ouviu? Eu vou consentir porque tenho pena de mandá-la para longe numa época fria, mas quando o tempo esquentar eu não posso mais ficar com ela em casa.

$\mathrm{O}$ primeiro trem larga três passageiros para o ônibus. $\mathrm{O}$ motorista endireita a almofada do seu assento. A moça está com a luz do seu olhar aprisionada pelo ombro terno do motorista. Através dos ombros, o vento matinal de outono vai se escoando para trás.

Alcança a diligência. Esta, encosta na beira da estrada.

- Obrigado.

Carroça puxada por um homem.

- Obrigado.

Cavalo.

- Obrigado.

- Obrigado.

- Obrigado.

Ele torna as montanhas e os campos, dos quinze $r i$ do seu percurso, repletos de gratidão e retorna para o pequeno porto, que fica na extremidade sul da península.

Este é um ano de farta colheita de caqui e de um belo outono nas montanhas.

Tradução de Silvana Regina Mertins

Revisão de Meiko Shimon

\section{Castidade sob o Telhado}

Estarei a sua espera às quatro da tarde na colina do parque.

Estarei a sua espera às quatro da tarde na colina do parque.

Estarei a sua espera às quatro da tarde na colina do parque.

Ela enviou a mesma carta pelo correio expresso para três homens. Para um homem que anda com uma bengala, para um homem que usa óculos e para um homem que não usa nem bengala, nem óculos.

Às três horas da tarde de março, na colina, ela florescia serena como uma flor de yûgao. Ao seu redor, os brotos tenros, que pela primeira vez, esta manhã, receberam suaves toques do ar em suas cútis delicadas, lamentavam, nas extremidades dos ramos das árvores, a chegada do seu primeiro entardecer. 
O homem com a bengala debaixo do braço vinha subindo a colina. Deve ser mérito da bengala. É certo que foi a bengala que farejou: que ela envia, todos os dias, as cartas expressas para alguns homens e que o homem que chegar mais cedo significa, para ela, a noite daquele dia.

Ela abriu um belo sorriso, como se tivesse nascido ao mundo neste instante. Ia descer correndo a colina, com seus calcanhares inocentes; então, parou um instante, fechando os olhos com gravidade, fez o sinal da cruz sobre o rosto.

- Senhor Deus. Agradeço ao Senhor por conceder-me mais esta noite, por meio deste senhor, uma noite de sono tranqüilo numa hospedaria, para mim que sou tão criança. E, se eu puder sobreviver até o dia de amanhã, rogo para que me conceda, também amanhã, por meio de um filho seu, uma noite de repouso em algum lugar.

Depois, ela se aconchegou graciosamente no homem. Então, da base da colina, as casas desta grande cidade observavam-na friamente. Lançando o olhar sobre a cidade, como se fosse algo ofuscante, ela falou:

- Ó telhados, telhados, telhados! Ó, incontáveis telhados que erguem suas pequenas cabeças para a imensidão do céu! Ó, vocês que são deuses protetores da castidade das mulheres! Cada um de vocês protege, cada qual, com profunda benevolência a castidade de uma mulher! E assim, eu passo cada noite sob diferente telhado e durmo essa noite com um sono tão casto, em respeito ao telhado que me acolheu! Oh, qual será o meu telhado desta noite? Porque o telhado de uma noite é o único que não tem raiva de mim -

Assim, ela e o homem desapareceram nas ruas da cidade.

Tradução de Meiko Shimon

\section{Cortar as Unhas pela Manhã}

Era uma moça pobre que alugava a parte de cima de uma casa pobre.

E esperava um dia para se casar com seu namorado. Entretanto, todas as noites aparecia um homem diferente ao seu encontro. Era uma casa que não recebia os raios do sol matinal. Ela costumava calçar tamancos velhos e gastos de homem e lavar roupas nos fundos da casa.

À noite, os homens sempre perguntavam.

- Mas como! Você não tem um mosquiteiro?

- Desculpe. Eu vou ficar acordada à noite e espantar os mosquitos para você. Perdoe-me.

Então ela, timidamente, acendia um incenso verde, repelente de mosquito. Depois de apagar a luz, contemplando a pequena luz do incenso que queimava, ela sempre recordava de seus dias de criança, enquanto ficava abanando o corpo do homem com um abano. Ela passava a noite sonhando que mexia o abano sem cessar.

Já é o começo do outono.

Um senhor idoso (era raro aparecer um visitante desta idade) subiu até o pobre segundo andar.

- Você não vai colocar um mosquiteiro?

- Desculpe. Eu vou ficar acordada à noite e espantar os mosquitos para o senhor. Perdoeme.

- Humm. Fique esperando aqui que eu não demoro, disse ele.

Então, ela correu até ele, que já havia se levantado, e falou.

- Eu vou espantar os mosquitos até o amanhecer. Não vou dormir nem um pouquinho.

- Está bem. Eu volto logo, disse ele. 
E, descendo a escada, o velho desapareceu. Com a luz acesa, a moça queimava o incenso repelente. No claro e sozinha, ela era incapaz de recordar a sua infância.

Decorrida cerca de uma hora, o velho retornou. Ela levantou-se de um salto.

- Hum, pelo menos você tem ganchos para pendurar, não é?

E o velho pendurou naquele quarto pobre um mosquiteiro branco inteiramente novo. A moça entrou no mosquiteiro e caminhou ${ }^{12}$, suspendendo a barra de seu quimono de dormir, sentindo o coração palpitar ante o toque agradável do tecido novo.

- Como eu tinha certeza que o senhor voltaria, esperei-o com a luz acesa. Agora quero ficar no claro, admirando mais o mosquiteiro branco.

Entretanto, a moça caiu num sono profundo que não tivera em alguns meses. Nem mesmo notou quando o velho foi embora pela manhã.

- Ei! ei! ei!

Ela despertou ao som da voz do seu namorado.

- Finalmente, amanhã poderemos nos casar! anunciou ele. - Ah, que mosquiteiro bom! Só de ver sinto a alma lavada.

Ao dizer isto, ele desprendeu o mosquiteiro, deixando-o cair por inteiro. Então, puxou a moça que ficara por baixo e jogou-a sobre o mosquiteiro.

- Sente em cima deste mosquiteiro! Você parece uma grande flor de lótus branca. Assim, este quarto agora é puro como você.

Pelo toque do linho novo, a moça se sentiu uma noiva de branco.

- Vou cortar as unhas dos pés, disse ela.

E assim, ela sentou-se sobre o mosquiteiro branco que cobria todo o quarto e começou a cortar, inocentemente, as esquecidas unhas longas de seus pés.

Tradução de Gilberto Brandão dos Santos

Revisão de Meiko Shimon

\section{Bibliografia}

HATORI, Tetsuya. "Izu no odoriko ni tsuite" In HATORI, Tetsuya. Sakka Kawabata no tenkai. Tóquio, Kyôiku Shuppan Sentâ 1993.

MATSUZAKA, Toshio. "Natsu no kutsu ron". In MATSUAKA, Toshio. Kawabata Yasunari

"Tanagokoro no shôsetsu" kenkyû. Tóquio, Kyôiku Shuppan, 1983.

12. Mosquiteiro japonês semelhante a uma barraca. Tem forma quadrada e é preso nos quatro cantos. 